\title{
Distribution Law of In Situ Stress and Its Engineering Application in Gateroad Maintenance: A Case Study
}

\author{
Guangchao Zhang, ${ }^{1,2}$ You Li $\mathbb{D}^{1},{ }^{1}$ Guangzhe Tao ${ }^{D},{ }^{1}$ Miao Chen ${ }^{D},{ }^{1}$ Ruihua Xu, ${ }^{2}$ \\ Hanqing Guo, ${ }^{2}$ Devkota Bidit, ${ }^{1}$ Guanglei Zhou, ${ }^{1}$ Zhi Qu, ${ }^{1}$ and Hao Zuo ${ }^{1}$ \\ ${ }^{1}$ College of Energy and Mining Engineering, Shandong University of Science and Technology, Qingdao 266590, China \\ ${ }^{2}$ Shandong Energy Group Co., Ltd., Jinan 250014, China \\ Correspondence should be addressed to You Li; liyou0239@163.com and Guangzhe Tao; tgz17854282741@163.com
}

Received 22 November 2021; Accepted 5 February 2022; Published 3 March 2022

Academic Editor: Gangwei Fan

Copyright (C 2022 Guangchao Zhang et al. This is an open access article distributed under the Creative Commons Attribution License, which permits unrestricted use, distribution, and reproduction in any medium, provided the original work is properly cited.

\begin{abstract}
In this study, the stress relief method of hollow inclusion and mathematical-statistical analysis are used to study the in situ stress distribution law of the Guotun coal mine, and the optimization strategy of roadway support is put forward. The test site is located in the city of Heze, Shandong Province, China. The main conclusions included the following: (1) among the three large-scale tectonic movements experienced by the Guotun coal mine, the middle Yanshan period has the strongest impact on it. According to the geological evolution process, it is preliminarily inferred that the maximum principal stress direction of the Guotun coal mine is northwest by west to southeast by east (NWW SEE). (2) Compared with the surrounding mines, the average value of the maximum principal stress in the Guotun coal mine is slightly higher, and there is a significant difference in the direction of in situ stress. The arc structure within the mine is the main reason for the deflection of the stress direction. (3) The lateral pressure coefficients $K_{H}, K_{h}$, and $K_{a v}$ show a nonlinear distribution with increased depth, and the three coefficients have a decreasing trend. The value of the stress gradient in the Guotun coal mine is greater when it is compared with the surrounding mines. (4) Field tests show that the new strategy proposed in this study is effective, which provides a good reference for engineering practice under similar geological conditions.
\end{abstract}

\section{Introduction}

In situ stress is the fundamental force that causes the deformation and failure of the surrounding rock in underground caverns, civil buildings, slopes, and other geotechnical engineering structures $[1,2]$. With the increase in the energy demand in China, coal mining has entered a state of deep mining [3]. Due to the higher mining intensity and the more complex distribution of in situ stress, large deformation of the deep gateroad, damage of the support structure, and other disasters that frequently occur $[4,5]$, a basic consensus has been reached in the mining industry that the design of mining gateroad and control of surrounding rock deformation should start with in situ stress measurement and analysis $[6,7]$.

To date, a number of studies have been conducted to investigate in situ stress measurement methods and equipment, field measurement, and its distribution law in China. For example, Cai et al. [8] proposed a device for in situ stress measurement based on complete temperature compensation and further put forward the calculation method for in situ stress. Kang et al. [9] presented a smallaperture hydraulic fracturing in situ stress measurement method and applied it in Luan, Jincheng, Fenxi, and other mining areas in China. Wang et al. [10] performed field monitoring to investigate the in situ stress distribution law of the Ping ding shan mining area. Synn et al. [11] analyzed the regional in situ stress pattern using 460 stress measurement data at about 100 test sites in Korea. A theoretical model was used to explain the effect mechanism of in situ stresses on crack propagation due to blasting by Yi et al. [12], and they supposed that the high in situ stresses can influence the crack propagation in the far field. Yang et al. [13] analyzed the stability of the hydrocarbon wells, by measuring the value of 
the in situ stress in the South Pars field. All these studies have improved our understanding of the in situ stress measurement and its engineering application.

tAt present, there are hundreds of measurement technologies in the world, which can be divided into three categories according to the measurement principle. The first is the mechanical method based on the measurement of strain and deformation in the rock mass, such as the stress recovery method, stress relief method, and hydraulic fracturing method. The second type is the geophysical method based on measuring the changes in acoustic emission, acoustic wave propagation law, resistivity, or other physical quantities in the rock mass. The third type is to determine the stress direction according to the information provided by geological structure and underground rock mass failure. Among them, the stress solution method and hydraulic fracturing method are widely used, and the other methods can only be used as auxiliary methods. Hydraulic fracturing method and hollow inclusion casing drilling method have been widely used and have been successfully commercialized. These two methods are also the key methods recommended by the International Committee on rock mechanics test methods in 2003.

It is well known that the distribution of in situ stress is closely related to the geological structure and exhibited evident regional distribution characteristics [13-17]. The Guotun coal mine is located in the southwest of Shandong province, with a complex geological structure and a maximum mining depth of $900 \mathrm{~m}$. With the progress of mining activities in the mine, the deformation and damage phenomena often occur in the gateroad, which has seriously affected the safe and efficient production of the mine. In addition, no systematic in situ stress test has been carried out in the mining area currently under mining. Therefore, it has become an urgent problem to study the in situ stress of the Guotun coal mine and improve the relevant support scheme.

The objective of this study is to develop a better understanding of the distribution characteristics of in situ stress and its engineering application in the Guotun coal mine. This study is organized as follows: in Section 1, the analysis of the geological structure evolution process and in situ stress direction was first presented. In Section 2, the process of in situ stress measurement is described in detail, and according to the result curve, the magnitude and direction of the in situ stress field are revealed. The variation law of principal stress and the lateral pressure coefficient with depth are discussed in this study. In Section 3, the control measures for large deformation of gateroad were proposed in the Guotun coal mine, and its validity was verified by a field application. The results presented in this study have important theoretical and practical implications for the exploitation of coal resources and the construction of gateroad engineering structures in the Guotun coal mine.

\section{Engineering Background and In Situ Stress Direction Prediction}

2.1. Engineering Geology Conditions. The Guotun coal mine is located in $3 \sim 17 \mathrm{~km}$ south of Yuncheng county in Heze city, Shandong Province, and the mine center is about $10 \mathrm{~km}$ away from Yuncheng county. It is the second pair of large modern mines planned and constructed in Juye coalfield and is currently the important coal resource-producing area in Shandong province. The mine covers an area of $69.33 \mathrm{~km}^{2}$, with geological reserves of 475 million tons and recoverable reserves of 165 million tons. The current mining seam is \#3 coal seam, with an average thickness of $4.73 \mathrm{~m}$. The average buried depth of the main coal seam is $808 \mathrm{~m}$. The thickness of the overlying Cenozoic stratum in the minefield is 530 650 m, mainly composed of clay, sandy clay, and sand. The roof of the coal seam is mainly fine sandstone and mudstone, with an average thickness of $7.5 \mathrm{~m}$, which is a relatively stable rock stratum; the coal seam floor is mainly composed of mudstone and carbonaceous mudstone, with an average thickness of $8.37 \mathrm{~m}$, which is a stable rock stratum. The structural complexity of the Guotun coal mine is medium, mainly monoclinic structure with north-south strike and east dip; the east boundary of the mine is Tianqiao fault, and the west boundary is coal seam outcrop; the stratum is gentle in the west and south and steep in the north and east. The main faults and folds of the mine are shown in Table 1.

2.2. Evolution Law of the Geological Structure and Principal Stress Direction Analysis. The geological structure of the Guotun coal mine is mainly controlled by the Juye mining area. In geological history, the Guotun coal mine has mainly experienced three large-scale tectonic movements, namely, Indosinian movement, Mid-Yanshan movement, and Late Yanshan movement [16]. The influence of geological tectonic movement on in situ stress field is different in each period.

The first stage was Indosinian movement, which led to strong fold uplift and fault movement in the whole coal accumulation basin in North China. The collision between the north and south continental blocks in the E-W direction formed E-W folds and faults, such as Yuncheng fault and Heze fault. The tectonic movement in this period formed the boundary of the Guotun coal mine.

The second stage is the Middle Yanshanian period. Due to the combined action of lateral tension of mantle plastic flow and plate edge compression, N-W compression weakens, and S-N normal faults controlling the occurrence of coal measure strata are widely developed. The tectonic movement in this period formed Xiangyang, Wangdong, Balihe, and other faults. These faults cut the interior of the Guotun mine and have a severe impact on the geological structure of the whole Guotun mine. Up to now, it is still the main geological structure of the Guotun coal mine.

The third stage was the Late Yanshanian period. When the plate extrusion replaced the mantle stress, the Guotun coal mine block was subjected to the extrusion and offset as a whole, gradually forming an arc structure. Then, it was subjected to the tension and torsion of many different rotation directions, forming a large number of uplifts, such as Balihe anticline and Guotun syncline.

At the present stage, the Guotun coal mine is mainly controlled by Tianqiao, Tianqiaozhi, Hongmiao, Balihe, 
TABLE 1: List of main structures of Guotun coal mine.

\begin{tabular}{|c|c|c|c|c|c|}
\hline \multirow{2}{*}{ Number } & \multirow{2}{*}{ Name of the geological structure } & \multirow{2}{*}{ Extension length (m) } & \multicolumn{3}{|c|}{ Fault occurrence/Range (m) } \\
\hline & & & Fault throw & Dip & Dip angle \\
\hline 1 & Tianqiao fault & 7.5 & $>500 \mathrm{~m}$ & East & $70^{\circ}$ \\
\hline 2 & Balizhuang fault & 12 & $0 \sim 150 \mathrm{~m}$ & West & $70^{\circ}$ \\
\hline 3 & Balihe fault & 10 & $0 \sim 150 \mathrm{~m}$ & West & $70^{\circ}$ \\
\hline 4 & Dongdong fault & 6.5 & $0 \sim 40 \mathrm{~m}$ & East & $70^{\circ}$ \\
\hline 5 & Xiangyang fault & 4.5 & $0 \sim 150 \mathrm{~m}$ & West & $70^{\circ}$ \\
\hline 6 & Houying fault & 3 & $170 \mathrm{~m}$ & West & $70^{\circ}$ \\
\hline 7 & Dingguantun anticline & 15 & & $2 \sim 150 \mathrm{~m}$ & \\
\hline 8 & Balihe anticline & 15 & & $20 \sim 80 \mathrm{~m}$ & \\
\hline 9 & Dinglichang syncline & 15 & & $20 \sim 240 \mathrm{~m}$ & \\
\hline 10 & Guotun syncline & 15 & & $50 \sim 300 \mathrm{~m}$ & \\
\hline
\end{tabular}

Xiangyang, Dongzhang, Balizhuang, Houxin, and other structures, which indicated that the Guotun coal mine is obviously affected by the compressive stress in the NW-SE direction. From the above analysis, it can be concluded that the main stress direction of the coal mine should be NWWSEE, as shown in Figure 1.

\section{The In Situ Stress Measurement and Its Distribution Characteristics in Guotun Coal Mine}

\subsection{In Situ Stress Measurement}

3.1.1. The Selection of Measuring Equipment and Point Location. The "recommended method for determining rock stress" was promulgated by the committee on test methods of the international society for rock mechanics in 1987. They confirmed the following four measurement methods as recommended methods: flat-jack method, hydraulic fracturing method, USBM borehole diameter deformation gauge method, and CSIRO hollow inclusion strain gauge method. The hollow inclusion stress resolution method is the best method to obtain the three-dimensional stress state. Therefore, the hollow inclusion stress solution method is selected for this in situ stress measurement. The main equipment diagram is shown in Figure 2 that mainly includes the following:

(i) The hollow inclusion triaxial stress meter $K X$-2011: its outstanding advantages are that the bonding quality between the stress gauge and the hole wall rock is great, and the measurement error caused by the temperature difference is eliminated.

(ii) The mine pressure monitoring substation KJF327-F: the accuracy can reach $0.1 \%$, and the lowest strain difference is $1 \mu \mathcal{\varepsilon}$, sensitivity coefficient is 0.001 999.999.

(iii) The other equipment includes confining pressure calibrator, strain gauge driver, and data processing software.

The selection of measuring points shall meet the following requirements. First, it needs to be representative, and it is necessary to avoid goaf and the complex geological structure. Second, consideration must be given to production, staff safety, the impact of measurement, and the production processes. Third, the borehole must be located in the same rock stratum. Based on the above selection principles, combined with the geological mining conditions and engineering practice background of the Guotun coal mine, five measuring points are finally selected, as shown in Figure 3. The technical characteristics of each measuring point are shown in Table 2.

3.1.2. Measurement Process and the Key Steps. The research team conducted a detailed in situ stress analysis in the No. 234 mining area of the Guotun coal mine from 2019 to 2020. The measurement process and the key steps are shown in Figure 4 as follows:

Step 1. Drilling geological holes. First, a large measuring hole is drilled with a hole depth of 1.5 2 times the gateroad width and a diameter of $130 \mathrm{~mm}$. Then, a conical drill bit is used to drill a conical variable diameter guide hole with a depth of $6 \sim 8 \mathrm{~cm}$. Finally, a small drill bit is used with a diameter of $36 \mathrm{~mm}$ to drill a measuring hole with a hole depth of $35 \sim 40 \mathrm{~cm}$.

Step 2. Install the stress gauge. First, the drilling hole is cleaned with cotton yarn, hole washer, and acetone. Then, epoxy adhesive is prepared in proportion and the length of the small hole is measured. Finally, the stress meter, positioner, and guide rod are installed in sequence, and finally, the conductor is protected.

Step 3. Measure the hole parameters. First, the positioner and guide rod are taken out in turn. Then, the azimuth and dip angles of the borehole are measured by the standard geological compass.

Step 4. Stress relief. First, the strain gauge is checked. Then, the release distance is marked and the drill is started. Next, the drilling rig is pushed while injecting water and data acquisition is carried out. Finally, when the reading of the strain gauge tends to be stable, releasing is stopped and the core is taken out with a stress gauge. 


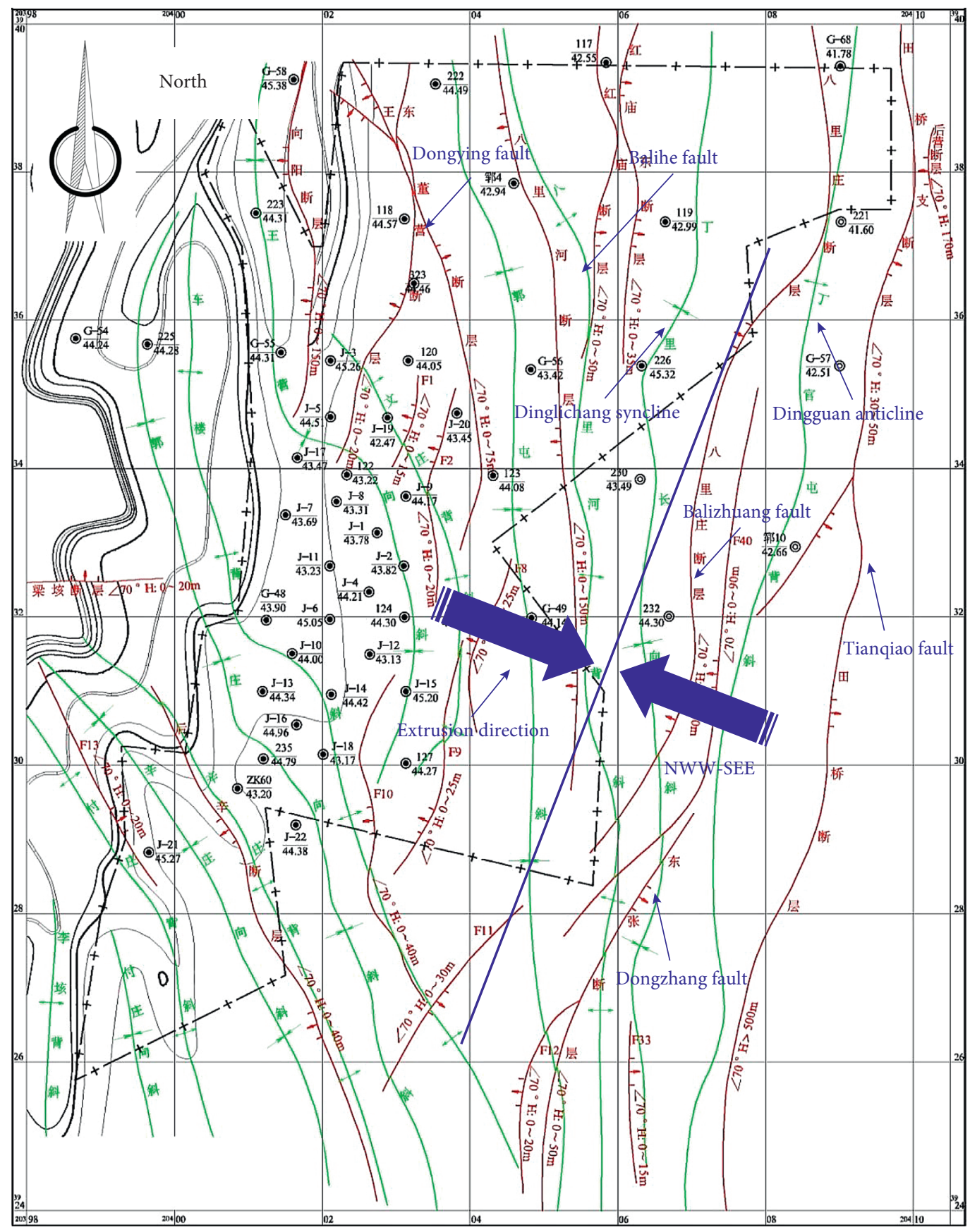

Figure 1: Analysis diagram of main stress direction of Guotun coal mine.
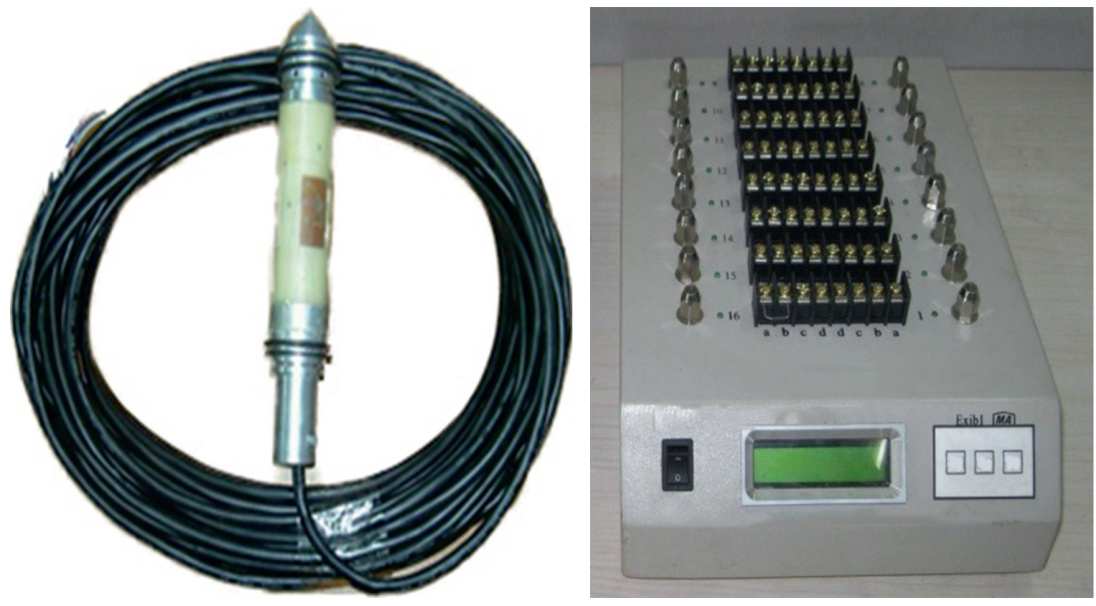

FIGURE 2: Main equipment for in situ stress measurement. 


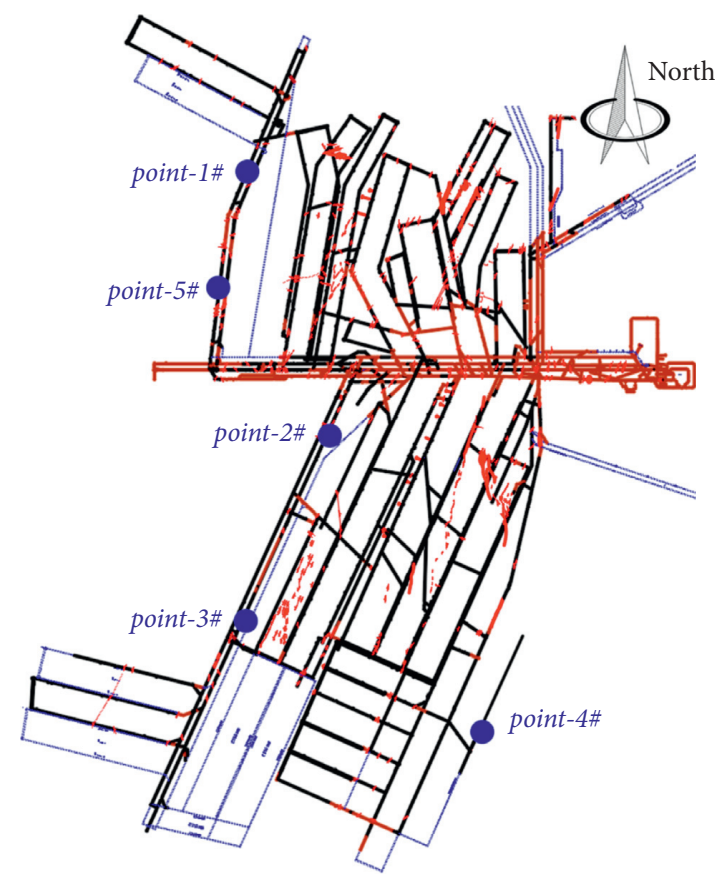

FIGURE 3: Location distribution of measuring points.

TABLE 2: Technical characteristics of measuring points.

\begin{tabular}{|c|c|c|c|c|c|c|c|c|}
\hline $\begin{array}{l}\text { Point } \\
\text { number }\end{array}$ & $\begin{array}{l}\text { Measuring point } \\
\text { position }\end{array}$ & $\begin{array}{l}\text { Hole depth } \\
\text { (m) }\end{array}$ & $\begin{array}{l}\text { Buried depth } \\
(\mathrm{m})\end{array}$ & $\begin{array}{c}\text { Azimuth } \\
\left({ }^{\circ}\right)\end{array}$ & $\begin{array}{c}\text { Dip angle } \\
\left({ }^{\circ}\right)\end{array}$ & $\begin{array}{l}\text { Elastic } \\
\text { modulus }\end{array}$ & $\begin{array}{l}\text { Poisson } \\
\text { ratio }\end{array}$ & Mounting angle \\
\hline $1 \#$ & Third area gateroad & 6.7 & 768 & 128 & 3.5 & 22700 & 0.29 & $0^{\circ}$ \\
\hline $2 \#$ & Gateroad \#2310 & 7.8 & 770 & 236 & 3.5 & 19800 & 0.20 & $0^{\circ}$ \\
\hline $3 \#$ & Gateroad \#2305 & 8.5 & 782 & 134 & 4 & 23800 & 0.26 & $0^{\circ}$ \\
\hline $4 \#$ & Fourth area gateroad & 8.2 & 801 & 131 & 5 & 19300 & 0.19 & $0^{\circ}$ \\
\hline $5 \#$ & Third area \#3303 & 7.6 & 795 & 124 & 3.5 & 28700 & 0.29 & $0^{\circ}$ \\
\hline
\end{tabular}

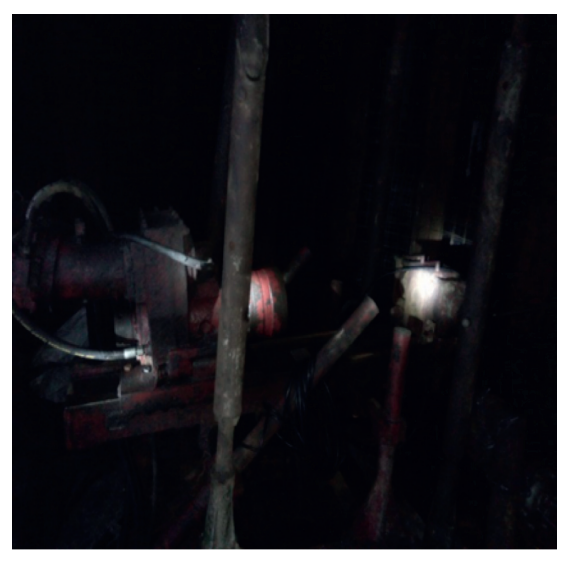

(a)

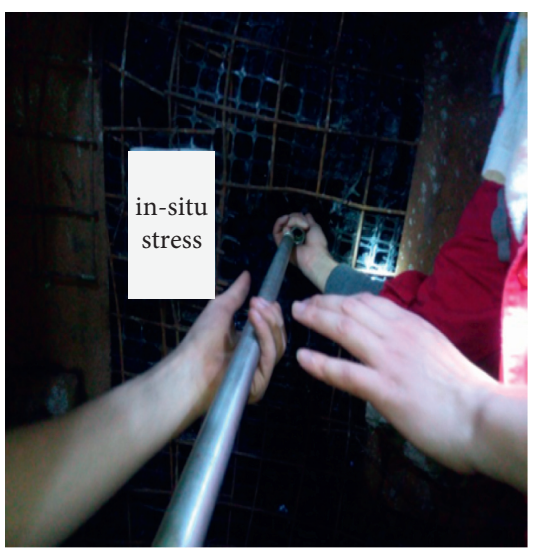

(b)

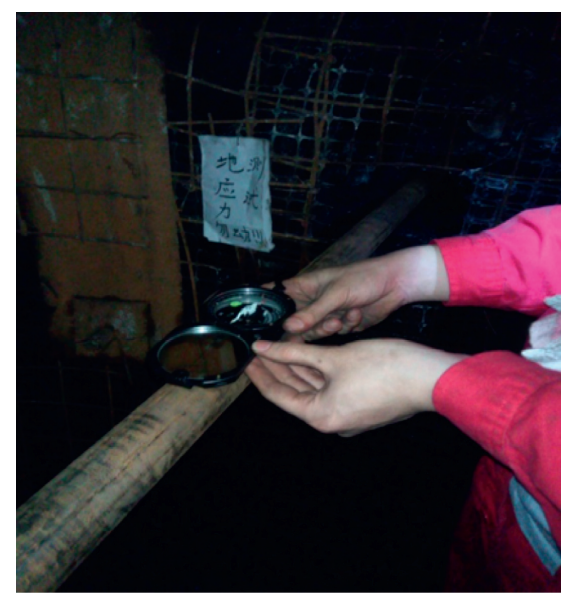

(c)

Figure 4: Continued. 


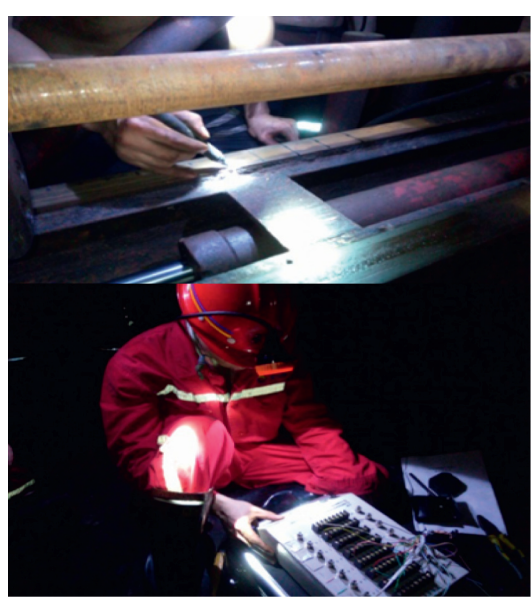

(d)

Figure 4: Key steps of field measurement. (a) Drill holes, (b) install stress gauge, (c) measure parameters, and (d) stress relief.

\subsection{Measurement Results and Analysis of the In Situ Stress Data}

3.2.1. In Situ Stress Measurement Results. Based on the strain values obtained from the above in situ stress measurement process and combined with the laboratory test, we got the $Y(n)$ curve, as shown in Figure 5. According to the stress relief curve, the stress relief process can be roughly divided into three stages [13].

In the first stage, when the stress relief surface does not reach the section where the strain gauge is located, the strain value monitored by each channel is small, which can be understood as the stress transfer of surrounding rock caused by the "excavation effect."

In the second stage, when the stress relief surface passes through the section where the strain gauge is located, the strain value gradually increases until it reaches the maximum value.

In the third stage, after the stress relief surface passes through the section where the strain gauge is located, the strain value monitored by each channel decreases to varying degrees and finally tends to be stable. The stable data are the initial strain data at the measured borehole.

The measurement results are processed by a computer program. It is a special in situ stress measurement and calculation program for hollow inclusion stress relief method designed by the Institute of Geomechanics, Chinese Academy of Geological Sciences in 2003. Its main interface is shown in Figure 6. The summary of calculation results is shown in Table 3.

3.2.2. Analysis of In Situ Stress Distribution. Based on the measured and existing data (a total of 9 measuring points) in the Guotun coal mine, this study analyzed the in situ stress field including its size and the direction variation law.

Distribution Characteristics of Principal Stress. According to the statistical analysis of the obtained in situ stress data, the maximum principal stress of the Guotun coal mine is
30.99 $\mathrm{MPa} \sim 56.56 \mathrm{MPa}$, with an average of $38.77 \mathrm{MPa}$. $[18,19]$ The intermediate principal stress is 19.17 $\mathrm{MPa} 27.85 \mathrm{MPa}$, with an average of 22.01 MPa. The minimum principal stress is $12.06 \mathrm{MPa} \sim 19.08 \mathrm{MPa}$, with an average of $15.95 \mathrm{MPa}$. The principal stress values of each measuring point are summarized on the grid, as shown in Figure 7.

Further analysis indicated that the Guotun coal mine is dominated by horizontal tectonic stress, and the types of in situ stress field are $\sigma_{H>} \sigma_{v} \sigma_{h}$. This strike-slip stress state is conducive to the preparation and activity of strike-slip faults. In addition, the stress values of all measuring points are above $30 \mathrm{MPa}$, belonging to the ultra-high stress area, and the stress gradient is $4.81 \mathrm{MPa} / 100 \mathrm{~m}$, which is larger than the surrounding mines. This may be attributed to the complex folds, faults, and other geological structures within the scope of the Guotun coal mine. Therefore, special attention should be paid to a series of stope dynamic phenomena caused by high stress.

Distribution Characteristics of Maximum Horizontal Principal Stress Direction. Figure 8 is a rose diagram of the dominant direction of the maximum horizontal principal stress in the Guotun coal mine. Statistics show that the dominant direction is distributed at $117^{\circ} \sim 134^{\circ}$, with an average of $123^{\circ}$, which is completely consistent with the macroanalysis results (NWW-SEE).

Therefore, it can be determined that the direction of in situ stress field in the Guotun coal mine is $N 57^{\circ} \mathrm{W}$. As can be seen from Figure 8, compared with the whole Shandong region, the maximum principal stress direction of the Guotun coal mine is within a reasonable range [20]. Compared with the adjacent mines (Yuncheng and Zhaolou), the adjacent mines are near E-W, while the direction of the Guotun coal mine deflects to the WN-ES. Based on the further analysis, we can infer that the main reason for the deflection to the WN-ES direction is a large number of arc structures (including folds and faults), which protrudes to the southeast, as shown in Figure 9. 


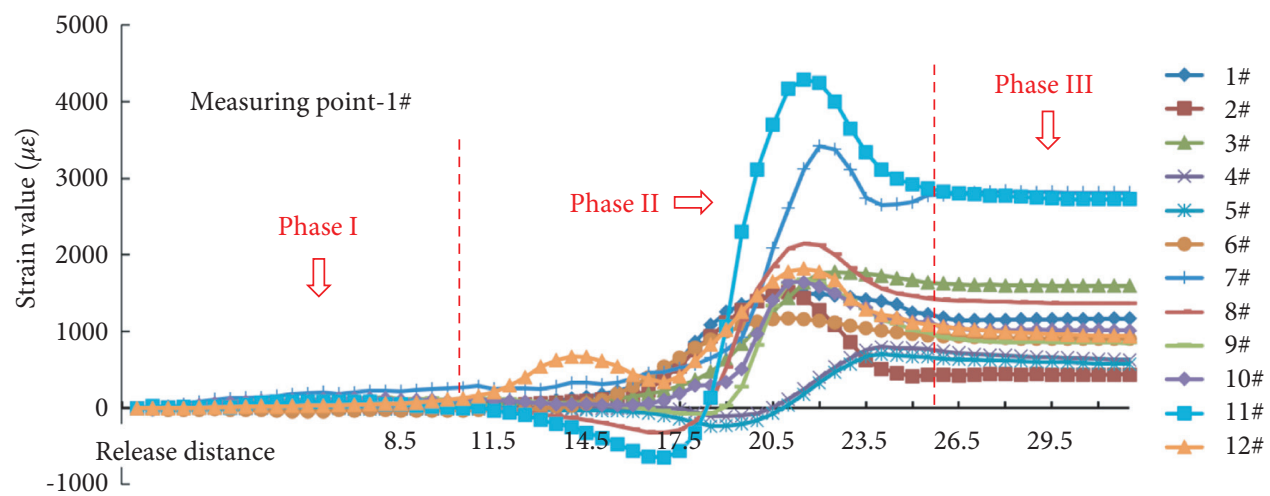

(a)

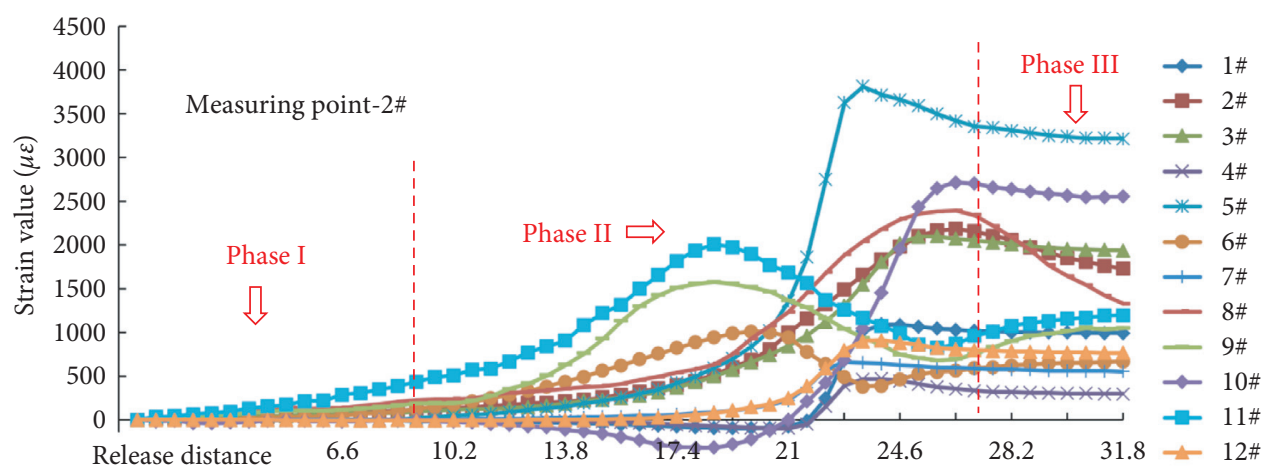
-1000 L

(b)

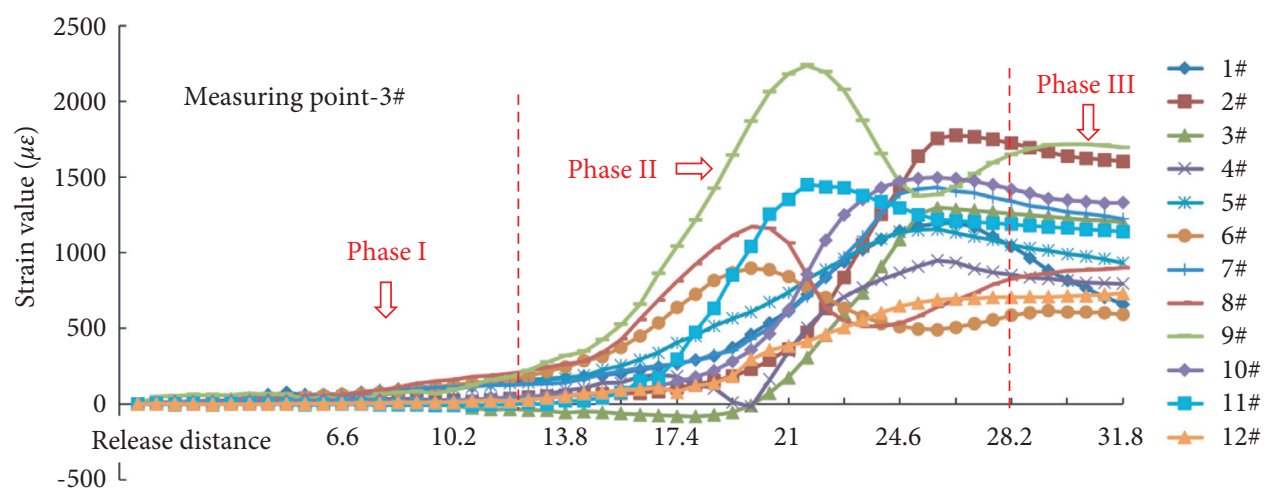

(c)

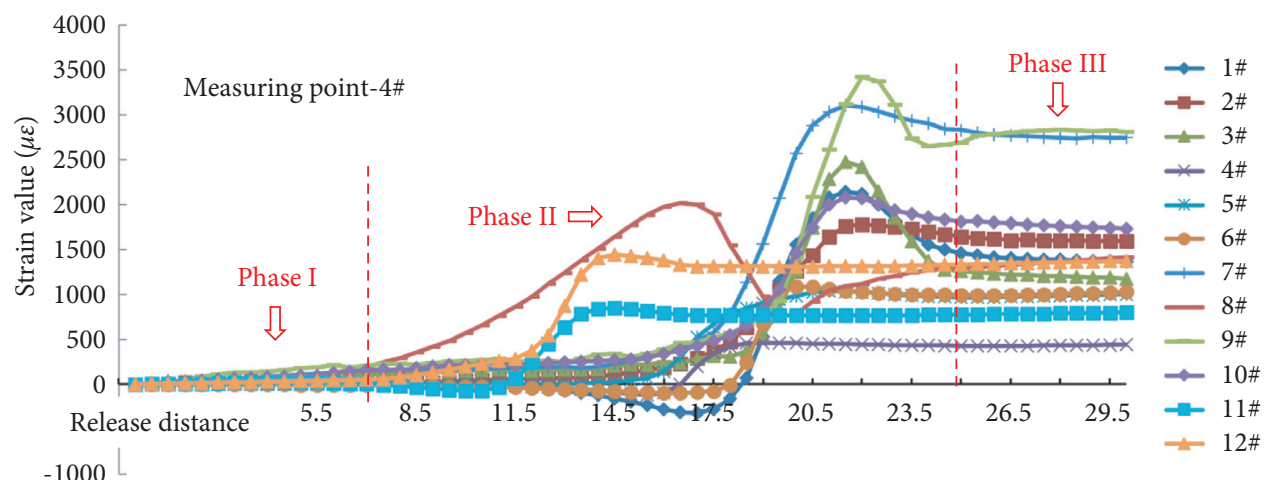

(d)

Figure 5: Continued. 


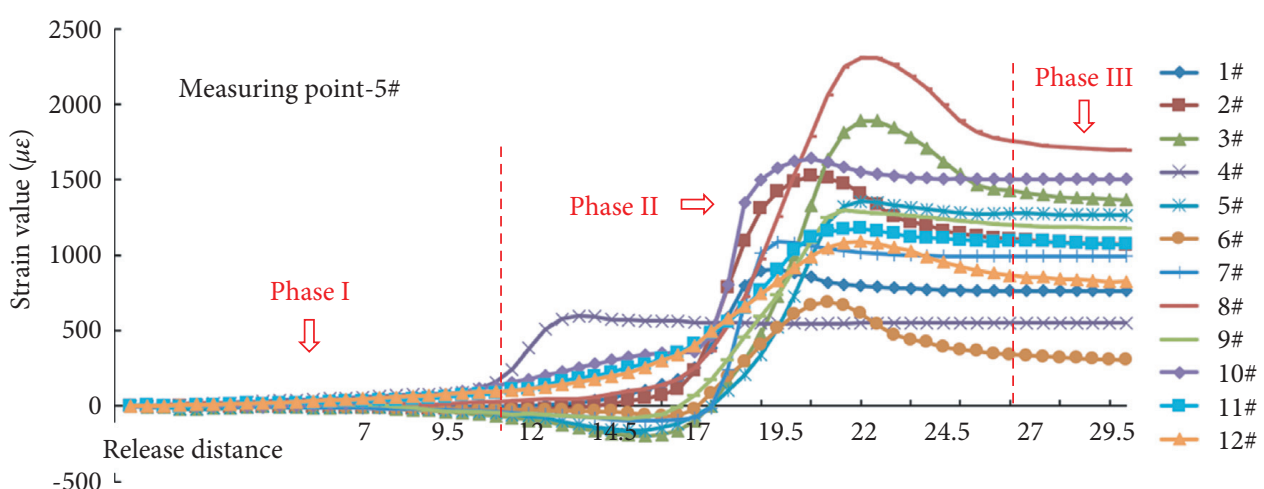

(e)

Figure 5: Stress relief curve.

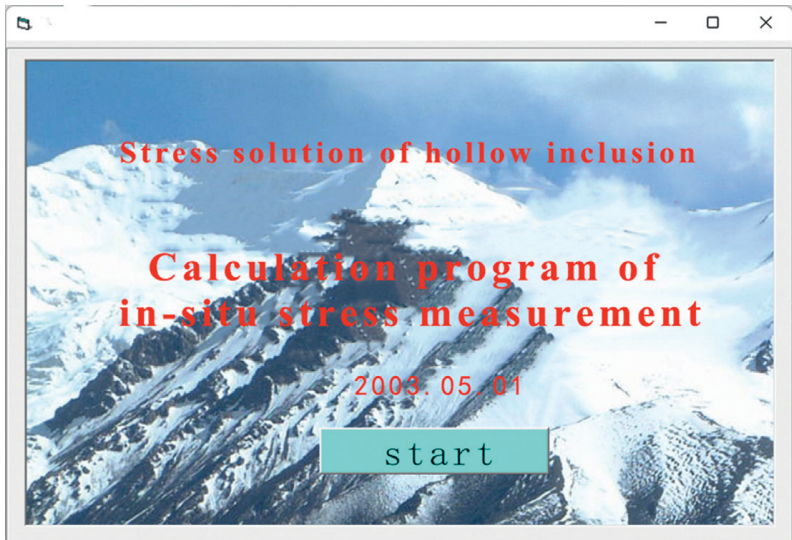

FIgURE 6: The main interface of in situ stress calculation program.

TABLE 3: Summary of measurement results.

\begin{tabular}{|c|c|c|c|c|c|}
\hline Number & Measuring point position & Principal stress & Value (MPa) & Dip angle & Azimuth \\
\hline \multirow{3}{*}{$1 \#$} & \multirow{3}{*}{ Third area gateroad } & $\sigma_{1}$ & 39.48 & $6^{\circ}$ & $122^{\circ}$ \\
\hline & & $\sigma_{2}$ & 21.35 & $83^{\circ}$ & $63^{\circ}$ \\
\hline & & $\sigma_{3}$ & 19.08 & $1^{\circ}$ & $212^{\circ}$ \\
\hline \multirow{3}{*}{$2 \#$} & \multirow{3}{*}{ Gateroad $\# 2310$} & $\sigma_{1}$ & 35.04 & $-11^{\circ}$ & $219^{\circ}$ \\
\hline & & $\sigma_{2}$ & 19.96 & $62^{\circ}$ & $73^{\circ}$ \\
\hline & & $\sigma_{3}$ & 12.06 & $25^{\circ}$ & $134^{\circ}$ \\
\hline \multirow{3}{*}{$3 \#$} & \multirow{3}{*}{ Gateroad \#2305 } & $\sigma_{1}$ & 35.02 & $3^{\circ}$ & $134^{\circ}$ \\
\hline & & $\sigma_{2}$ & 19.17 & $70^{\circ}$ & $36^{\circ}$ \\
\hline & & $\sigma_{3}$ & 14.39 & $19.7^{\circ}$ & $225^{\circ}$ \\
\hline \multirow{3}{*}{$4 \#$} & \multirow{3}{*}{ Fourth area gateroad } & $\sigma_{1}$ & 33.86 & $24^{\circ}$ & $126^{\circ}$ \\
\hline & & $\sigma_{2}$ & 20.01 & $61^{\circ}$ & $18^{\circ}$ \\
\hline & & $\sigma_{3}$ & 15.09 & $14^{\circ}$ & $223^{\circ}$ \\
\hline \multirow{3}{*}{$5 \#$} & \multirow{3}{*}{ Third area $\# 3303$} & $\sigma_{1}$ & 42.54 & $-6^{\circ}$ & $117^{\circ}$ \\
\hline & & $\sigma_{2}$ & 23.72 & $-78^{\circ}$ & $6^{\circ}$ \\
\hline & & $\sigma_{3}$ & 18.73 & $-9^{\circ}$ & $208^{\circ}$ \\
\hline
\end{tabular}




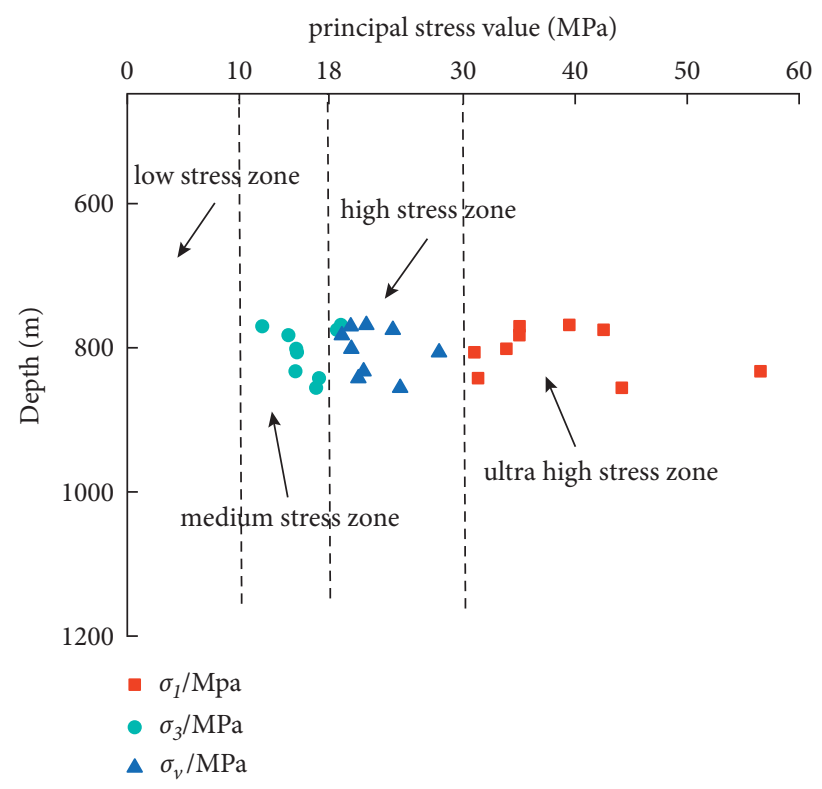

Figure 7: Distribution of principal stress.

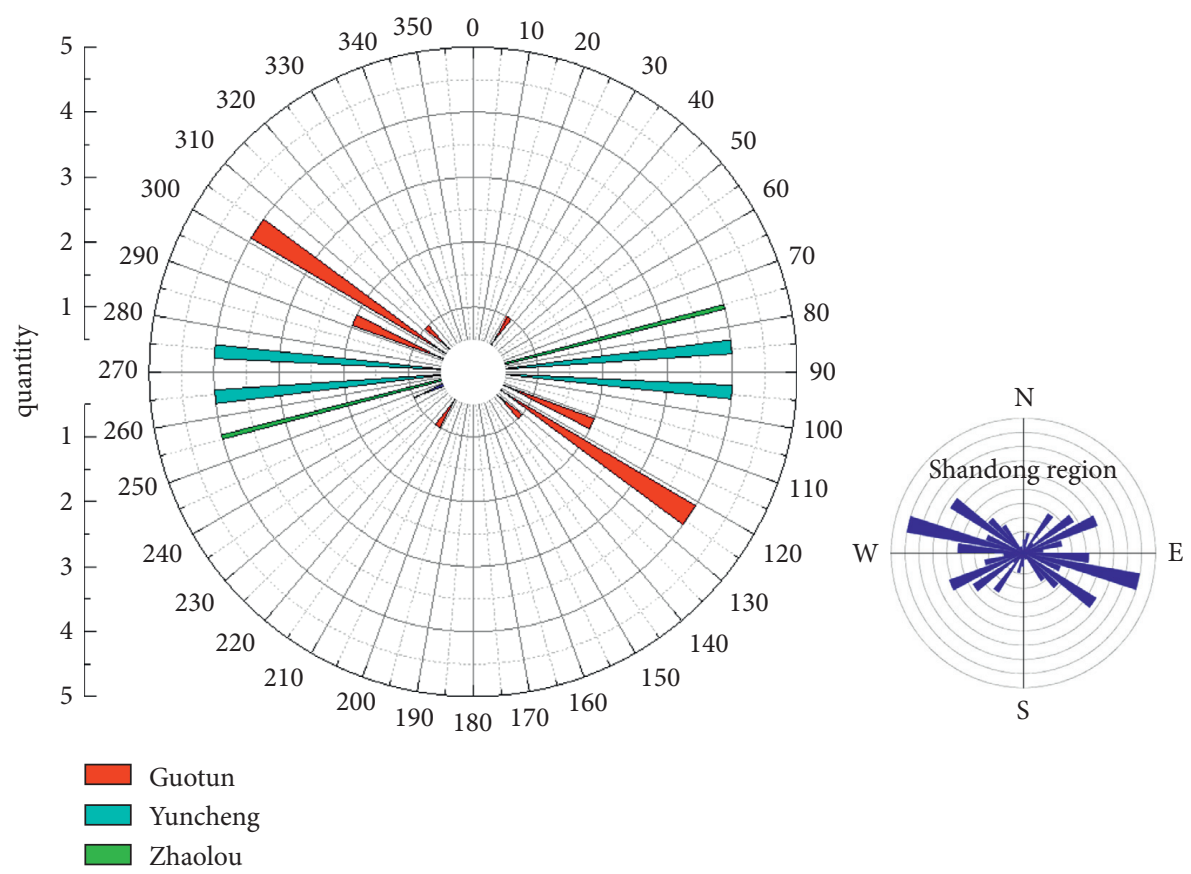

Figure 8: Rose diagram of the maximum principal stress [16].

Variation Law of Principal Stress with Depth. The maximum, minimum, and vertical principal stresses with the corresponding depth of each measurement point were plotted in Figure 10.

The least square method was used for linear regression fitting. The fitting results are as follows:

$$
\begin{aligned}
& \sigma_{1}=0.0453 H+14.419\left(R^{2}=0.90182\right), \\
& \sigma_{2}=0.0293 H+15.077\left(R^{2}=0.91381\right),
\end{aligned}
$$

$$
\sigma_{3}=0.0278 H+19.685\left(R^{2}=0.92271\right),
$$

where $H$ is the depth $(\mathrm{m})$, and $R^{2}$ is the correlation coefficient.

From equations (1)-(3), it can be concluded that a great fitting effect was obtained by the three main stress fitting equations with the correlation coefficient $R^{2}$ of greater than 0.9 . It can be also seen in Figure 10 that the principal stress value approximately linearly increases with the depth, and the maximum principal stress is slightly discrete. This may be 


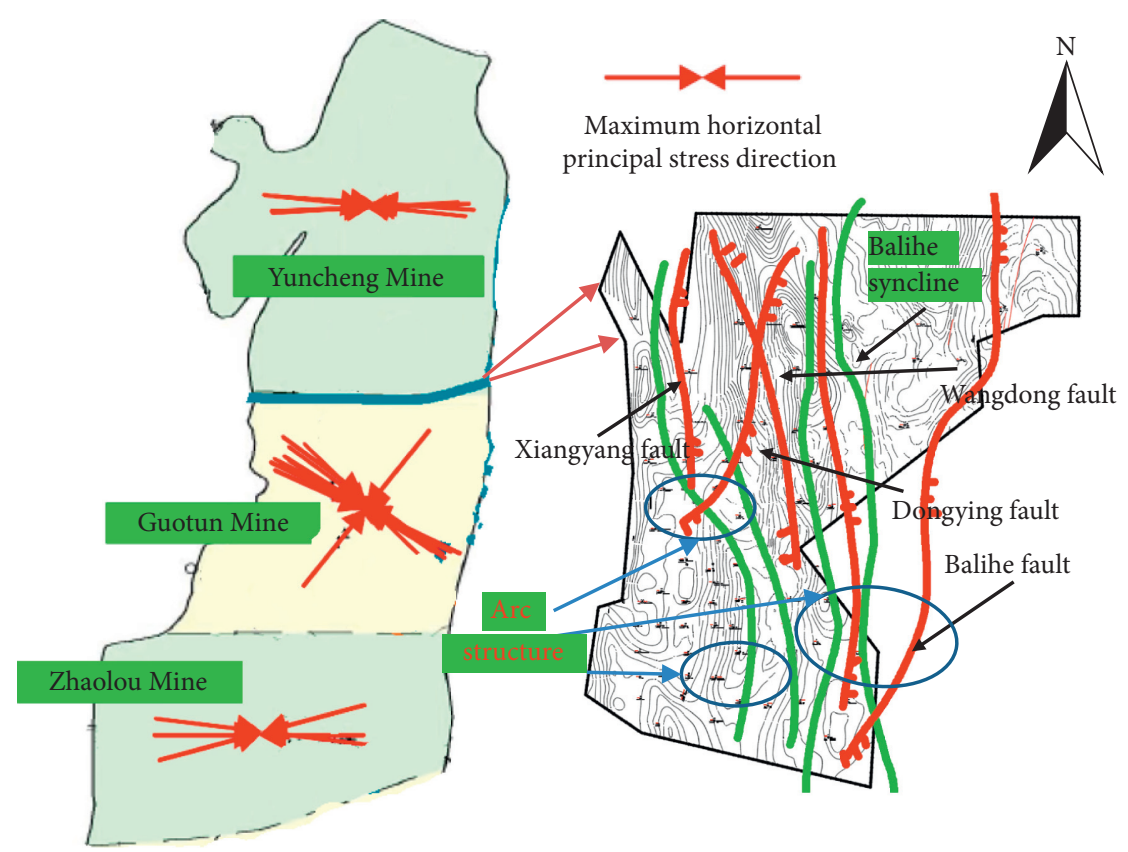

FIgURE 9: Directional distribution of the maximum horizontal principal stress.

caused by the differences in the geological structure and rock stratum characteristics in different degrees of the local range.

In the process of actual measurement, due to the unpredictability of the lithology of the measured rock mass and its fracture development degree, there will inevitably be errors in the measurement results. So, in order to verify the accuracy of the measurement results, the principal stress fitting results of the Guotun coal mine are compared with the surrounding coal mines, as shown in Table 4 . It can be inferred that the variation trend of $\sigma_{H}$ and $\sigma_{h}$ between the Guotun coal mine and the Zhaolou coal mine shows a great consistency on the whole, but the Guotun's stress gradient (slope of the fitting curve) is relatively large. Compared with the Yuncheng coal mine, the two regression equations are quite different, which may be caused by the different amount of data and statistical depth used in regression analysis.

Variation of the Lateral Pressure Coefficient with Depth. The lateral pressure coefficient is an important characterization of the in situ stress state, and its size has a very important reference value for the design, construction, and maintenance of mine gateroad engineering $[23,24]$. In this study, the ratios of $\sigma_{H}$ to $\sigma_{v}, \sigma_{h}$ to $\sigma_{v}$, and $\sigma_{(H+h) / 2}$ to $\sigma_{v}$ are denoted as $K_{H}, K_{h}$, and $K_{a v}$. They were used to analyze the variation law of the in situ stress state with depth. The curve function $K=a / H+b$ was used for regression fitting, and the results are as follows:

$$
\begin{gathered}
K_{H}=\frac{72.71}{H+1.57}, \\
K_{h}=\frac{56.54}{H+0.63}, \\
K_{a v}=\frac{101.21}{H+1.12} .
\end{gathered}
$$

Figure 11 shows the fitting curves of three lateral pressure coefficients varying with depth. It can be concluded that the distribution of $K_{H}, K_{h}$, and $K_{a v}$ shows a great regularity. According to the statistical results, the value of $K_{H}$ is 1.11-2.68, with an average of 1.78 , the $K_{h}$ value is $0.54-0.89$, with an average of 0.73 , and the $K_{a v}$ is $0.83-1.70$, with an average of 1.26. In general, with increased depth, the values of the three lateral pressure coefficients have a decreasing trend. From formulas (4) (6), it can also be inferred that $K_{H}, K_{h}$, and $K_{a v}$ are likely to approach $1.57,0.63$, and 1.12 , respectively.

\section{Surrounding Rock Control Measures and Application}

The stability of roadway surrounding rock is mainly affected by horizontal stress and can be divided into three areas: first, slightly affected areas; second, medium impact area; and third, seriously affected areas. The roadway parallel to the maximum horizontal stress direction is the least affected, and the surrounding rock stability is the best. For the roadway intersecting with the maximum horizontal stress direction at an acute angle, the surrounding rock deformation tends to a certain side of the roadway, and the surrounding rock stability is general. The roadway perpendicular to the maximum horizontal stress direction is most affected by horizontal stress, and the stability of surrounding rock is the worst.

In engineering practice, correctly handling the relationship between gateroad support design and in situ stress is an important guarantee for the safe mining of coal mine $[25,26]$. The above-measured results and distribution law provide a detailed and reliable basis for gateroad mining layout and support scheme design. In this study, optimizing mining layout and strengthening support were proposed and 


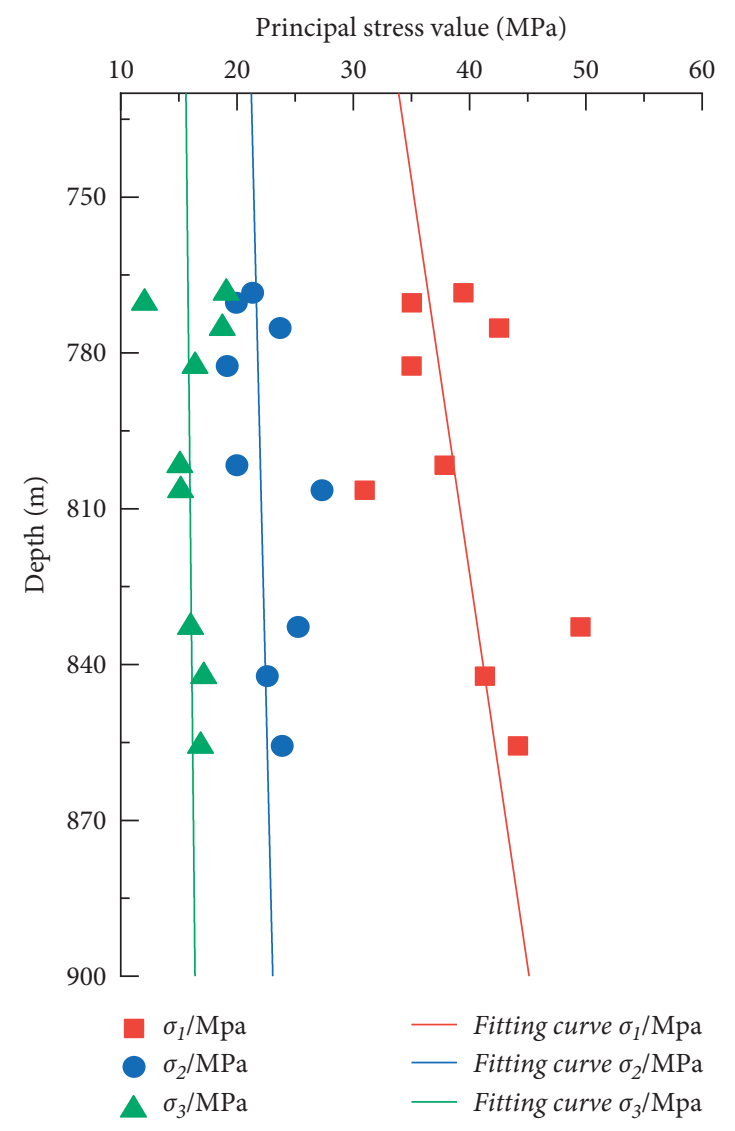

FIGURE 10: Fitting curve of principal stress with buried depth.

TABLE 4: Comparison of principal stress variation with depth between Guotun and other mines.

\begin{tabular}{|c|c|c|c|c|}
\hline$\sigma_{H}$ & $\sigma_{h}$ & $\sigma_{v}$ & Mine & Source \\
\hline $0.0453 H+14.419\left(R^{2}=0.90182\right)$ & $0.0278 H+19.685\left(R^{2}=0.92271\right)$ & $0.0293 H+15.077\left(R^{2}=0.91381\right)$ & Guotun & This paper \\
\hline $0.0384 H+4.78\left(R^{2}=0.7918\right)$ & $0.0276 H+4.34\left(R^{2}=0.8960\right)$ & - & Zhaolou & Chen et al. [21] \\
\hline $0.3256 H-235.299\left(R^{2}=0.9503\right)$ & $0.1250 H-84.191\left(R^{2}=0.8121\right)$ & $0.2256 H-161.199\left(R^{2}=0.9942\right)$ & Yuncheng & Peng et al. [22] \\
\hline
\end{tabular}

carried out field application, based on the distribution law of in situ stress in the Guotun coal mine.

\subsection{Control Measures for Large Deformation of Gateroad.} First, working face 3301 is one of the typical working faces being mined. One of the measuring points of this in situ stress measurement is selected near the working face. Second, the overburden of working face 3301 has the typical stratigraphic characteristics of the Guotun coal mine. Therefore, gateroads of working face 3301 are selected as the site for the field application of the support scheme in this study.

The detailed technology parameters should be determined based on the existing economic and technical conditions, relevant theories, and engineering practice. Taking the working face 3301 of the Guotun coal mine as an example, the coal seam has stable occurrence, simple structure, and average thickness of $5.65 \mathrm{~m}$. The roof is mainly fine and siltstone, and the floor is mainly mudstone and siltstone. A rectangular gateroad with width of $4.6 \mathrm{~m}$, height of $4.3 \mathrm{~m}$, and net sectional area of
$19.78 \mathrm{~m}^{2}$ is used for solid coal or semicoal rock excavation. The specific control measures are as follows:

4.1.1. Optimizing Mining Layout. First, the gateroads should be excavated along the direction of the maximum principal stress or at an acute angle with it as far as possible. It means that the gateroad in the Guotun coal mine should be arranged along the N57W direction as far as possible. Considering the specific engineering geological and construction conditions of the working face 3301, the angle between the direction of excavation and the maximum principal stress is set to 8 degrees. The specific layout of gateroad is shown in Figure 12.

Second, the gateroad layout should avoid large geological structures (fault, fold, and collapse column) as far as possible.

4.1.2. Strengthen the Support Scheme. First, the anchor bolts. Anchor bolts with yield strength greater than $500 \mathrm{MPa}$ and easy to install shall be selected to enhance the adaptability to 

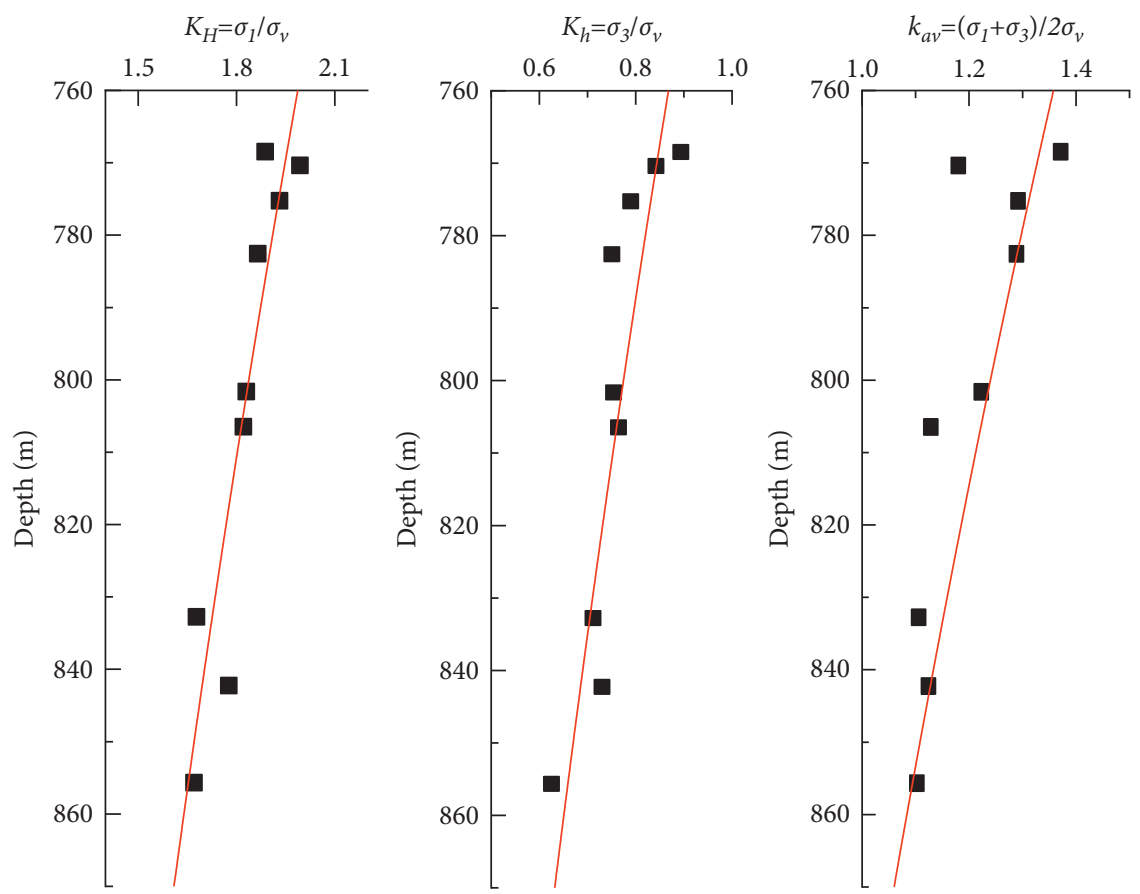

Figure 11: Relationship between lateral pressure coefficient and buried depth.

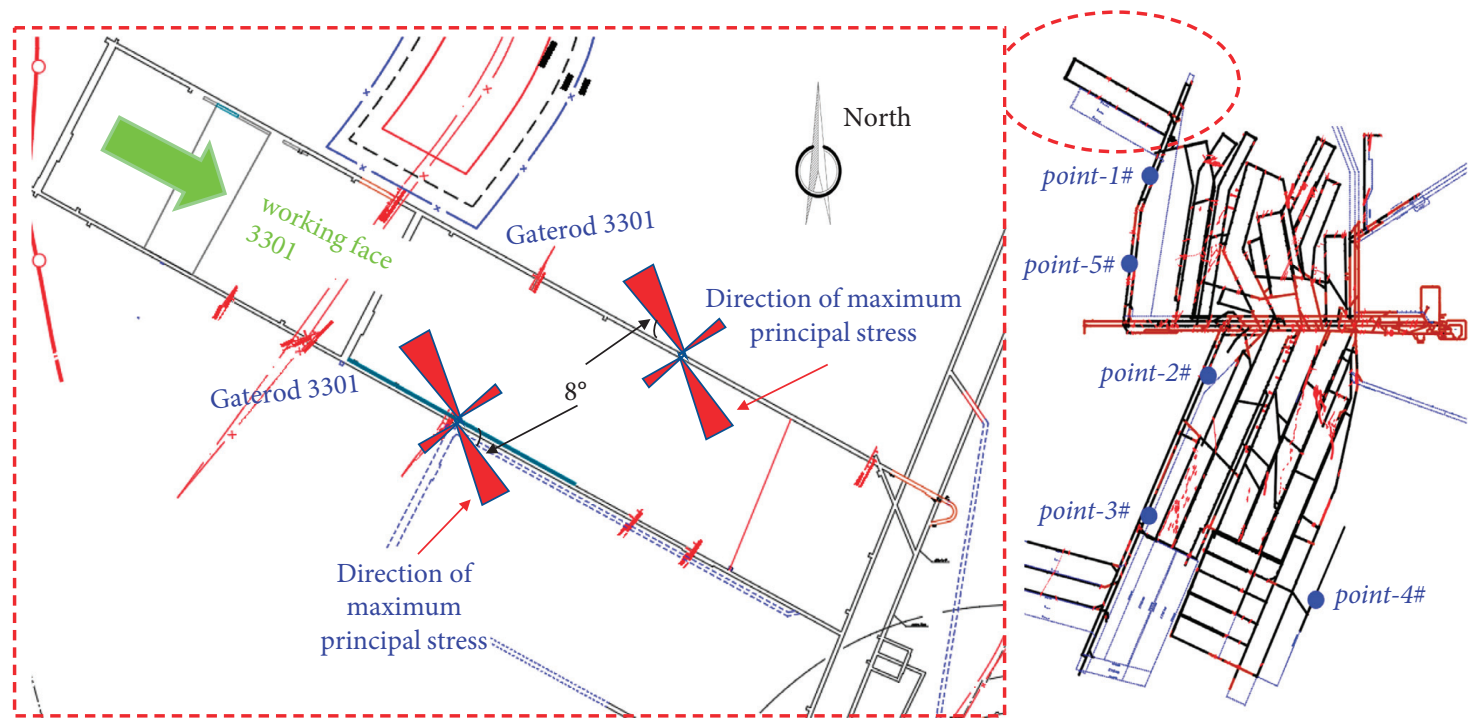

Figure 12: General layout of gateroad at working face 3301.

roof and coal wall. Especially for broken surrounding rock, when there are local irregularities, the ribs and roof can be smoothly pasted. Six left-handed high-strength prestressed bolts with a $20 \mathrm{~mm}$ diameter, a $2,400 \mathrm{~mm}$ length, and $500 \mathrm{MPa}$ tensile strength were used in the roof. Five righthand threaded steel bolts without longitudinal reinforcement with $20 \mathrm{~mm}$ in diameter and 3,300 $\mathrm{mm}$ in length were installed in the two ribs of the gateroad. All the bolts were installed with a spacing of $900 \mathrm{~mm} \times 900 \mathrm{~mm}$, a capsule resin $\mathrm{K} 2370$, and a $150 \mathrm{~mm} \times 150 \mathrm{~mm} \times 10 \mathrm{~mm}$ anchor bolt tray [27-31].
Second, the anchor cable. The type of $1 \times 19 \#$ highstrength anchor cable is chosen, which can make the anchor cable to have better diffusion prestressing effect in the preloading stage and strong antideformation ability in the working stage. Three left-handed steel strand anchor cables with a $22 \mathrm{~mm}$ diameter and $8 \mathrm{~m}$ length are used in the gateroad roof. The anchor cable beam is processed with 14\# channel steel (yield strength limit $235 \mathrm{MPa}$ ). All the bolts were installed with a spacing of $1,800 \mathrm{~mm} \times 900 \mathrm{~mm}$ and two capsule resin K2370 [32-35]. The large diameter thickened anchor cable tray (bearing capacity $560 \mathrm{kN}$ ) is used with the 


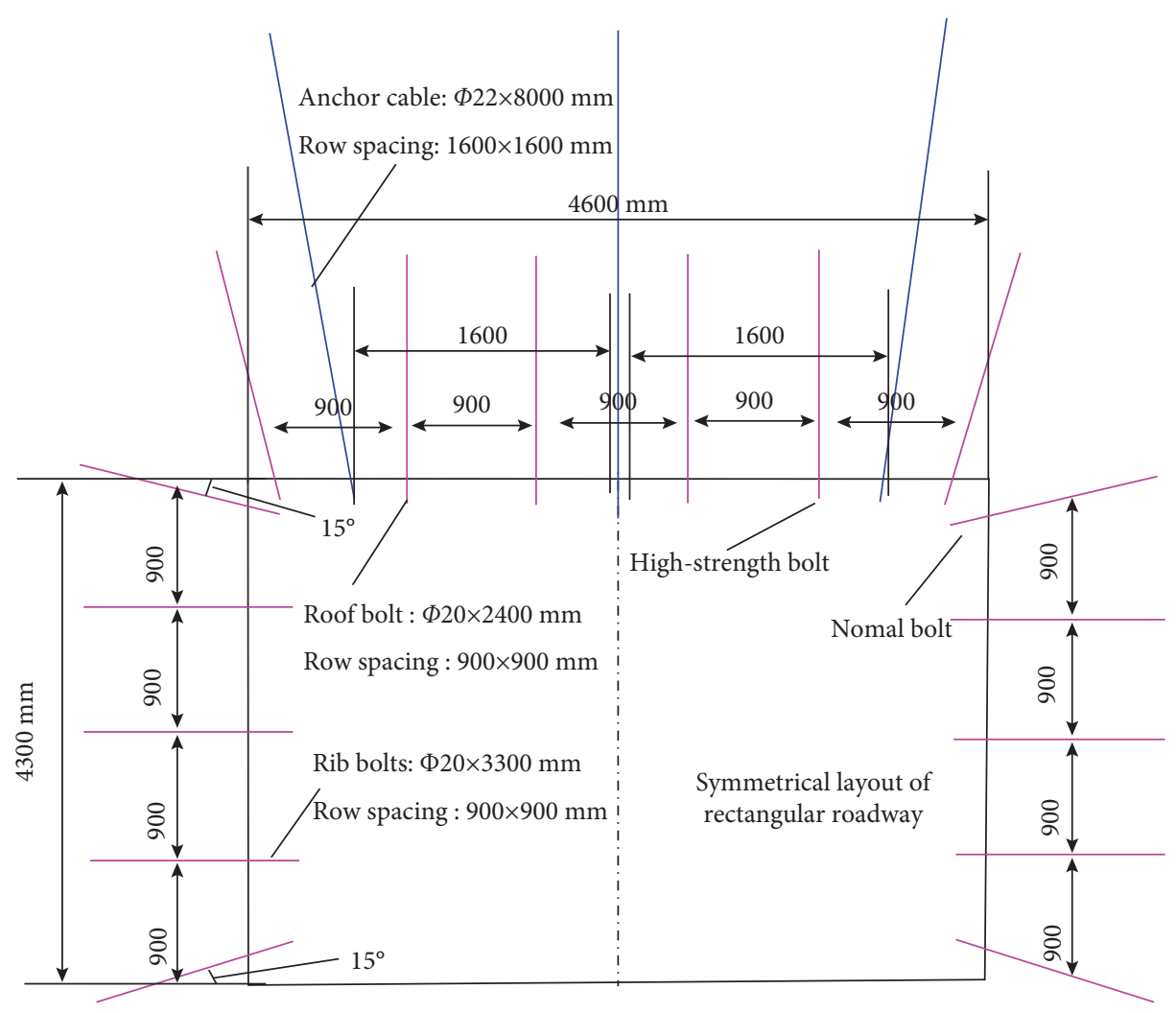

FIGURE 13: Support scheme 3301.

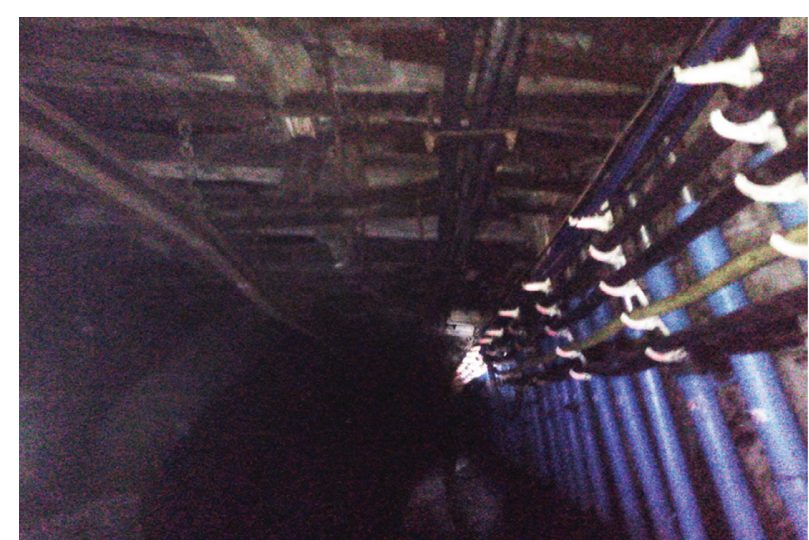

FIGURE 14: Roof support effect of working face 3301.

size of $150 \mathrm{~mm} \times 150 \mathrm{~mm} \times 10 \mathrm{~mm}$, and the anchor cable layout is " $3-2-3$."

Third, protection of the gateroad surface. The gateroad surface is protected by metal mesh and high-strength impact-resistant woven mesh at the same time, which can effectively prevent the roof from breaking and falling. Gateroad roof and two sides can be laid $\Phi$ $6 \mathrm{~mm} \times 1,100 \mathrm{~mm} \times 2,000 \mathrm{~mm}$ metal mesh (yield strength $380 \mathrm{MPa}$ ) and high-strength tensile plastic, with plastic mesh inside and metal mesh outside. The plastic mesh shall be overlapped for $100 \mathrm{~mm}$, a buckle shall be connected every $300 \mathrm{~mm}$, and the mesh wire shall be 12\# iron wire. The specific support scheme is shown in Figure 13.
4.2. Analysis of Surrounding Rock Control Effect. After the above layout method and support scheme are used in the mining gateroad of working face 3301, we use the roof separation instrument to monitor the displacement of relevant areas. The monitoring results show that the deformation of two ribs and the roof was within the control range. During the gateraod excavation, the deformation of both ribs and the roof was within the control range. The cumulative subsidence of the roof was $200 \mathrm{~mm}$, the two ribs' convergence was $200 \mathrm{~mm}$, and there was no floor heave. During the panel retreat period, the deformation of the gateroad slightly increased, and the overall deformation is always at a low level. The roadway could meet the 
requirements of the ventilation and normal mining of the working face. The field support effect is shown in Figure 14.

\section{Conclusions}

This study mainly focuses on the distribution law of in situ stress field in the Guotun coal mine, and the specific control measures for surrounding rock are presented. The main conclusions are as follows:

(1) Among the three large-scale tectonic movements experienced by the Guotun coal mine, the middle Yanshan period has the strongest impact on it. According to the geological evolution process, it is preliminarily inferred that the maximum principal stress direction of the Guotun coal mine is NWW SEE.

(2) The field measurement results show that the average maximum principal stress of the Guotun coal mine is $38.77 \mathrm{MPa}$, and the direction is 123 (N57W). Compared with the adjacent mines, the NW deflection is obvious, which is mainly caused by the arc structure within the mine.

(3) The type of in situ stress field in the Guotun coal mine is $\sigma_{H}>\sigma_{v}>\sigma_{h}$. The average stress gradient is $4.81 \mathrm{MPa} / 100 \mathrm{~m}$. The maximum principal stress linearly increases with the depth and is larger than the surrounding mines. The lateral pressure coefficients $K_{H}, K_{h}$, and $K_{a v}$ are likely to approach 1.57 , 0.63 , and 1.12 , respectively.

(4) The field test shows that the large deformation control measures proposed in this study to optimize the mining layout and strengthen the support have significant effects.

\section{Data Availability}

The data used to support the findings of this study are included in the article.

\section{Conflicts of Interest}

There are no conflicts of interest regarding the publication of this paper.

\section{Acknowledgments}

This is work was supported by the National Natural Science Foundation of China (nos. 51904164 and 52004145) and the Natural Science Foundation of Shandong Province (ZR2018QEE001 and ZR2020QE119).

\section{References}

[1] T. Bai, H. Yang, X.-B. Chen, S. C. Zhang, and Y. S. Jin, "In-situ monitoring and reliability analysis of an embankment slope with soil variabilit," Geomechanics and Engineering, vol. 23, no. 3, pp. 261-273, 2020.
[2] Ł. Bednarek and T. Majcherczyk, "An analysis of rock mass characteristics which influence the choice of support," Geomechanics and Engineering, vol. 21, no. 4, pp. 371-377, 2020.

[3] H.-P. Kang, B.-D. Yi, F.-Q. Gao, and H.-W. Lv, "In-situ stress database and its distribution in China's coal mines," Journal of China Coal Society, vol. 44, no. 1, pp. 23-33, 2019.

[4] K. Bandyopadhyay, J. Mallik, and T. Ghosh, "Dependence of fluid flow on cleat aperture distribution and aperture-length scaling: a case study from Gondwana coal seams of Raniganj Formation, Eastern India," International Journal of Coal Science \& Technology, vol. 7, no. 1, pp. 133-146, 2020.

[5] A. J. Das, P. K. Mandal, P. S. Paul, and R. K. Sinha, "Generalised analytical models for the strength of the Inclined as well as the flat coal pillars using rock mass failure criterion," Rock Mechanics and Rock Engineering, vol. 52, no. 10, pp. 3921-3946, 2019.

[6] L.-Y. Huang, S.-X. Yang, X.-F. Cui, Q.-C. Chen, and R. Yao, "Analysis of characteristics of measured stress and stability of faults in North China," Chinese Journal of Geophysics, vol. 36, no. 1, pp. 204-213, 2013.

[7] Y. M. Cheng, J. A. Wang, G. X. Xie, and W. B. Wei, “Threedimensional analysis of coal barrier pillars in tailgate area adjacent to the fully mechanized top caving mining face," International Journal of Rock Mechanics and Mining Sciences, vol. 47, no. 8, pp. 1372-1383, 2010.

[8] M.-F. Cai, Q.-F. Guo, Y. Li, Z.-F. Du, Z.-F. Du, and J.-H. Liu, "Geostress measurement and its application in pingmei mine," Chinese Journal of Engineering, vol. 35, no. 11, pp. 1399-1406, 2013.

[9] H.-P. Kang, T.-M. Jiang, X. Zhang, and L. Yan, "Research and application of in-situ stress field in Jincheng mining area," Chinese Journal of Rock Mechanics and Engineering, vol. 28, no. 1, pp. 1-8, 2009.

[10] Y.-C. Wang, H.-W. Jing, K.-F. Chen, and L.-Y. Wei, "Research on in-situ stress distribution and spatial zoning in Pingdingshan mining area," Chinese Journal of Rock Mechanics and Engineering, vol. 33, no. s1, pp. 2620-2627, 2014.

[11] J.-H. Synn, C. Park, and B.-J. Lee, "Regional distribution pattern and geo-historical transition of in-situ stress fields in the Korean peninsula," Tunnel and Under Ground Space, vol. 23, no. 6, pp. 457-469, 2013.

[12] C.-P. Yi, D. Johansson, and J. Greberg, "Effects of in-situ stresses on the fracturing of rock by blasting," Computers and Geotechnics, vol. 104, no. 1, pp. 321-330, 2017.

[13] J.-C. Yang, X.-D. Li, K.-W. Liu, and Z.-X. Liu, "Stress initialization methods for dynamic numerical simulation of rock mass with high in-situ stress," Journal of Central South University, vol. 27, no. 10, pp. 3149-3162, 2020.

[14] T. Hijazo and L. I. G. D. Vallejo, "In-situ stress amplification due to geological factors in tunnels: the case of Pajares tunnels, Spain," Engineering Geology, vol. 13, no. 20, pp. 137-138, 2012.

[15] H. Yavuz, "An estimation method for cover pressure re-establishment distance and pressure distribution in the goaf of longwall coal mines," International Journal of Rock Mechanics and Mining Sciences, vol. 41, no. 2, pp. 193-205, 2004.

[16] P. Li, Q.-F. Guo, H.-T. Liu, and X.-Q. Jiang, "Analysis on the characteristics of current in-situ stress field and stress accumulation level in Shandong province," Chinese Journal of Rock Mechanics and Engineering, vol. 36, no. 9, pp. 2220-2231, 2017.

[17] Y.-H. Wang, X.-F. Cui, X.-P. Hu, and F.-R. Xie, "Study on the stress state in upper crust of China mainland based on in-situ stress measurements," Chinese Journal of Geophysics, vol. 55, no. 9, pp. 3016-3027, 2012. 
[18] E. Komurlu, A. Kesimal, and R. Hasanpour, "In situ horizontal stress effect on plastic zone around circular underground openings excavated in elastic zones," Geomechanics and Engineering, vol. 8, no. 6, pp. 783-799, 2015.

[19] J. A. Smith, H. L. Ramandi, C. Zhang, and W. A. Timms, "Analysis of the influence of groundwater and the stress regime on bolt behaviour in underground coal mines," International Journal of Coal Science \& Technology, vol. 6, no. 2, pp. 286-300, 2019.

[20] G. Jepson, R. C. King, S. Holford, A. H. E. Bailey, and M. Hand, "In situ stress and natural fractures in the carnarvon basin, north west shelf, Australia," Exploration Geophysics, vol. 50, no. 5, pp. 514-531, 2019.

[21] M. Chen, S.-Q. Yang, P.-G. Ranjith, and Y.-C. Zhang, "Cracking behavior of rock containing non-persistent joints with various joints inclinations," Theoretical and Applied Fracture Mechanics, vol. 109, no. 1, pp. 1-16, 2020.

[22] H. Peng, X.-M. Ma, and J.-J. Jiang, "In situ stress measurement and stress field study of $1000 \mathrm{~m}$ deep hole hydraulic fracturing in Zhaolou coal mine," Chinese Journal of Rock Mechanics and Engineering, vol. 30, no. 8, pp. 1638-1645, 2011.

[23] J.-K. Li, G. Li, and Z.-J. Tian, "Application of hollow inclusion in in-situ stress test in Yuncheng coal mine," Industrial Safety and Environmental Protection, vol. 45, no. 4, pp. 15-19, 2019.

[24] M. Shabanimashcool and C. C. Li, "Analytical approaches for studying the stability of laminated roof strata," International Journal of Rock Mechanics and Mining Sciences, vol. 79, no. 1, pp. 99-108, 2015.

[25] M. M. Mohammed, H. Roslan, and S. Firas, "Assessment of rapid impact compaction in ground improvement from insitu testing," Journal of Central South University, vol. 20, no. 3, pp. 786-790, 2013.

[26] G.-L. Zhou, T. Xu, M. J. Heap et al., “A three-dimensional numerical meso-approach to modeling time-independent deformation and fracturing of brittle rocks," Computers and Geotechnics, vol. 117, no. 1, Article ID 103274, 2020.

[27] Y. Sun, J. Zuo, M. Karakus, L. Liu, H. Zhou, and M. Yu, “A new theoretical method to predict strata movement and surface subsidence due to inclined coal seam mining," Rock Mechanics and Rock Engineering, vol. 54, no. 6, pp. 27232740, 2021.

[28] W.-L. Shen, G.-C. Shi, Y.-G. Wang, J.-B. Bai, R.-F. Zhang, and X.-Y. Wang, "Tomography of the dynamic stress coefficient for stress wave prediction in sedimentary rock layer under the mining additional stress," International Journal of Mining Science and Technology, vol. 31, no. 6, pp. 653-663, 2021.

[29] G.-C. Zhang, C.-W. Zang, M. Chen, and T. Guangzhe, "Ground response of entries driven adjacent to a retreating longwall panel," International Journal of Rock Mechanics and Mining Sciences, vol. 138, no. 11, Article ID 104630, 2021.

[30] G. C. Zhang, Z. J. Wen, S. J. Liang et al., "Ground response of a gob-side entry in a longwall panel extracting $17 \mathrm{~m}$-thick coal seam: a case study," Rock Mechanics and Rock Engineering, vol. 53, no. 2, pp. 497-516, 2019.

[31] F. Cui, C. Jia, X.-P. Lai, and J.-Q. Chen, "Study on the evolution characteristics and stability of overburden structure in upward mining of short distance coal seams with strong burst tendency," Chinese Journal of Rock Mechanics and Engineering, vol. 39, no. 03, pp. 570-521, 2020.

[32] G.-C. Zhang, F.-L. He, H.-G. Jia, and Y.-H. Lai, "Analysis of gateroad stability in relation to yield pillar size: a case study," Rock Mechanics and Rock Engineering, vol. 50, no. 05, pp. 1263-1278, 2017.
[33] X. Li, G. Zhang, G. Tao et al., "Ground behaviors analysis of a stope covered by the thin bedrock and large-thick alluvium: a case study," Shock and Vibration, vol. 2022, Article ID 4759416, 14 pages, 2022.

[34] J.-H. Chen, P. Liu, H.-B. Zhao, C. Zhang, and J.-W. Zhang, "Analytical studying the axial performance of fully encapsulated rock bolts," Engineering Failure Analysis, vol. 128, no. 1, pp. 1-16, 2021.

[35] J.-H. Chen and D.-Q. Li, "Numerical simulation of fully encapsulated rock bolts with a tri-linear constitutive relation," Tunnelling and Underground Space Technology, vol. 120, no. 1, pp. 1-13, 2022. 